\title{
Stigma matters in ending tuberculosis: Nationwide survey of stigma in Ethiopia
}

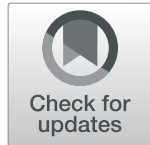

Daniel G. Datiko ${ }^{* *}$, Degu Jerene ${ }^{1}$ and Pedro Suarez ${ }^{2}$

\begin{abstract}
Background: Tuberculosis (TB) affects, and claims the lives of, millions every year. Despite efforts to find and treat TB, about four million cases were missed globally in 2017. Barriers to accessing health care, inadequate health-seeking behavior of the community, poor socioeconomic conditions, and stigma are major determinants of this gap. Unfortunately, TB-related stigma remains unexplored in Ethiopia.

Methods: This mixed methods survey was conducted using multistage cluster sampling to identify 32 districts and 8 sub-cities, from which 40 health centers were randomly selected. Twenty-one TB patients and 21 family members were enrolled from each health center, and 11 household members from each community in the catchment population.

Results: A total of 3463 participants (844 TB patients, 836 from their families, and 1783 from the general population) were enrolled for the study. The mean age and standard deviation were $34.3 \pm 12.9$ years for both sexes ( $34.9 \pm 13.2$ for men and $33.8 \pm 12.5$ for women). Fifty percent of the study participants were women; $32.1 \%$ were illiterate; and $19.8 \%$ came from the lowest wealth quintile. The mean stigma score was 18.6 for the general population, 20.5 for families, and 21.3 for TB patients. The general population of Addis Ababa (AOR: 0.1 [95\% Cl: 0.06-0.17]), those educated above secondary school (AOR: 0.58 [95\% Cl: 0.39-0.87]), and those with a high score for knowledge about TB (AOR: 0.62 [95\% Cl: 0.49-0.78]) had low stigma scores. Families of TB patients who attended above secondary school (AOR: 0.37 [95\% Cl: $0.23-0.61]$ ) had low stigma scores. TB patients educated above secondary school (AOR: 0.61 [95\% Cl: 0.38-0.97]) had lower stigma scores, while those in the first (AOR: 1.93: 95\% Cl 1.05-3.57) and third quintiles (AOR: 1.81: 95\% Cl: 1.08-3.05) had stigma scores twice as high as those in the highest quintile. Fear of job loss (32.5\%), isolation (15.3\%), and feeling avoided (9.3\%) affected disclosure about TB.
\end{abstract}

Conclusions: More than a third of Ethiopians have high scores for TB-related stigma, which were associated with educational status, poverty, and lack of awareness about TB. Stigma matters in TB prevention, care, and treatment and warrants stigma reduction interventions.

Keywords: Tuberculosis, Stigma, Ethiopia

\section{Background}

Tuberculosis (TB) is a worldwide public health crisis. A third of the world's population is infected, and 10 million people developed TB disease, while 1.6 million died of TB, in 2017. National TB Programs (NTPs) have diagnosed and treated millions of TB cases over the years. However, about 4 million TB cases were missed globally in 2017 alone [1]. This gap could be due to problems related to health service delivery and poor health-seeking

\footnotetext{
* Correspondence: dgemechu@msh.org; danieljohn42@yahoo.com

${ }^{1}$ Challenge TB/Ethiopia and Management Sciences for Health/Ethiopia, P.O.

Box 1157, Code 1250 Addis Ababa, Ethiopia
}

Full list of author information is available at the end of the article behavior of the community, which are affected by factors that include awareness about TB, gender, stigma, and constrained socioeconomic conditions [2-4].

Community health-seeking behavior is also affected by the accessibility of services, the availability and quality of services, and cultural factors. These vary by the type of health condition and the views and perceptions of the clients and communities, which are expressed in a range of behaviors, including stigma [4]. Stigma is described as social determinant of health because it is shaped by community norms, interpersonal relations, and health institutions' culture $[5,6]$. Unfortunately, people with

(c) The Author(s). 2020 Open Access This article is distributed under the terms of the Creative Commons Attribution 4.0 International License (http://creativecommons.org/licenses/by/4.0/), which permits unrestricted use, distribution, and 
living some diseases, including TB, HIV, and leprosy, face deep-rooted and longstanding stigma within the community $[7,8]$.

Understanding of stigma toward TB, unlike HIV, is limited [9]. TB is primarily a disease of the poor and is associated with high stigma in the community. In addition to the stigmatizing community response $[10,11]$, self-stigmatization by TB patients affects the will of TB patients to seek care and adhere to their treatment [12], which is also affected by the association of TB with HIV and negative cultural beliefs or norms [13]. Moreover, victim blaming by health workers and the community, such as associating TB with bad behavior on the part of patients, reinforces the grip of stigma in communities and the health system [14].

Studies have shown higher stigma among the poor, the less educated, women, and socially disadvantaged communities. However, the magnitude of stigma varies across settings and is worst when a person is discriminated against by society and household members, with negative consequences on marital life, quality of life, and future opportunities $[15,16]$.

Understanding perceptions about $\mathrm{TB}$ and community misconceptions is an entry to designing patient-centered services. Qualitative studies have reported that patients prefer to be treated well and receive adequate counseling at appropriate times, and want supportive mechanisms during their illness $[17,18]$. But negative perceptions about TB affect patients' capacity to disclose their disease status to relatives and family members. This has demoralized patients and resulted in selective disclosure of their status only to trusted community members [19]. However, in communities with better awareness about $\mathrm{TB}$, where health care workers are supportive and adequate patient support mechanisms are available, the magnitude of stigma was reported to be low [10].

Ethiopia has a high burden of TB, TB/HIV, and multidrug-resistant $\mathrm{TB}$, with comorbidities and high stigma $[8,9,20]$. Nearly $30 \%$ of estimated TB cases are still missed by the NTP. High stigma among the poor, women, and rural communities could be one of the factors contributing to the case detection gap [21-23]. However, there has been no large-scale study of TB-related stigma. Therefore, we aim to describe the magnitude of stigma related to TB in communities: TB patients, their families, and the general population of Ethiopia.

\section{Methods}

\section{Study setting and population}

This is the first national stigma survey conducted in seven regions and two city administrations of Ethiopia. The Challenge TB project operates in nine regions, covering $92 \%$ of the national population. The NTP started implementing the WHO-recommended DOTS strategy in 1995. Currently, 256 hospitals and 3390 health centers provide TB services, and over 16,000 health posts deliver community-based TB care. The community health services mainly focus on conducting regular health education sessions, identifying and referring presumptive TB cases, and providing adherence support. Despite these efforts, the NTP continues to miss a third of estimated cases [1].

\section{Study design and sampling}

This is a mixed methods study conducted from October to November 2017 in the nine Challenge TB-supported regions of Ethiopia.

\section{Sample size for the quantitative study}

A single population proportion formula was used to estimate sample size [24]. A design effect of 2 and $10 \%$ was added to compensate for the non-response rate. A total of 3463 participants were enrolled for the study: 1783 from the general population, 836 from families of TB patients, and $844 \mathrm{~TB}$ patients.

\section{Study area}

Ethiopia is administratively divided into nine regional states and two city administrations. This survey was conducted in seven regions and two city administrations. From these, 16 zones (provinces) and four sub-cities were selected. From each zone or sub-city, two districts were randomly selected. From each district, one rural and one urban kebele (lowest administrative unit with an average population of five thousands) were identified for the study. Finally, from the total of 40 districts selected, 80 kebeles were included in the study. The kebeles were divided into gots or clusters as the final study unit. Households were identified by systematic sampling, and 22 household participants were enrolled from each got or cluster.

Forty health centers were identified to enroll TB patients and their families. From each health center, we interviewed $11 \mathrm{~TB}$ patients and their families after obtaining informed consent. We recruited TB patients who were at least 18 years old who had been on treatment for at least 1 month. From their households, a household member who was at least 18 years old who had lived in the house for at least 6 months was selected by lottery.

\section{Qualitative studies}

We conducted 18 focus group discussions (FGDs) and 76 in-depth interviews (IDIs). The kebele administrators assisted the research team in the identification of participants. The participants in the IDIs were selected from program managers (10 regional, 8 provincial, and 10 district TB focal persons), 12 health care workers, $12 \mathrm{~TB}$ patients, 12 family members of TB patients, and 12 
health extension workers (HEWs), who are community health workers. TB patients and families of TB patients were approached in the health centers, while participants of FGD from the community were identified by kebele administrators.

\section{Data collection}

To collect quantitative data, we pre-tested and used semistructured questionnaires from the WHO guide, which contains a generic questionnaire for data collection about stigma and wealth index [(2)]. The questionnaire has variables related to perception of TB patients toward themselves, anticipated stigma from their households and the community, and enacted stigma that the patients had experienced.

Trained data collectors were employed for the study. Tablets for data collection used web-based CSPro software Version 7.2 (Census and Survey Processing System, US Census Bureau and ICF Macro; 2019).

FGDs and IDIs were conducted in the local languages by trained, experienced data collectors using pretested, semistructured, and open-ended topic guides. The FGDS and IDIs were audiotaped. Supervisors were assigned to conduct random data checks and household visits. Builtin validation checks (character, data type, range, limit, required fields, skip, etc.) were designed in the questionnaire, and a regular check was done by a central CSPro expert, the data manager.

\section{Data analysis}

Quantitative data were extracted from the web-based system and exported to IBM SPSS Statistics Version 25 (Armonk, NY, USA: IBM; 2019) for analysis. Descriptive analysis was done using SPSS. Binary logistic and multivariate logistic regression, for variables with $p<0.25$, were used.

Knowledge scores were constructed using the total number of interview questions employed to assess the knowledge of the study participants and the total number of expected correct answers. We calculated knowledge scores using the mean of the number of correct answers given by the study participants as a cut-off point to categorize the knowledge scores into high or low. The study participants who answered above the mean score were classified as having a high knowledge score, while those who answered below the mean score were classified as having a low knowledge score.

Wealth-related variables were initially constructed for rural and urban populations, and later a common wealth index was constructed using variables that were considered common both rural and urban areas. Finally, both the rural and urban wealth index regression coefficients were mapped into the common wealth index, resulting in a composite "national" wealth index, which was categorized into quintiles.

Qualitative data were imported to OpenCode software (version 3.6) and analyzed using thematic content analysis. Direct verbatim quotations and results from the coding and categorization were used to develop the narrative.

\section{Ethics approval and consent to participate}

Ethical clearance was obtained from the Ethics Review Board of the Ministry of Science and Technology. We obtained support letters from the Federal Ministry of Health. We also sought and received informed verbal consent from the study participants. The Ethics Review Board approved informed verbal consent for the study.

\section{Results}

\section{Sociodemographic and economic characteristics} General population

Among the 1783 study participants interviewed, the mean age $(\mathrm{SD})$ was 34.6 years $(\mathrm{SD} \pm 12.9)$. Of the total number of participants, 828 (46.8\%) were men, $48.7 \%$ of whom were heads of household, and $33.5 \%$ of whom were married. Among the study participants from general population, $66 \%$ were married, $22 \%$ were housewives, and $30.1 \%$ of the study participants could not read and write (Table 1).

\section{Families of TB patients}

Of the 836 family members of TB patients interviewed, the mean (SD) age was 33.8 (11.6). In this group, $48.7 \%$ were males, $39.4 \%$ were head of households, $65 \%$ were married, $33.9 \%$ were illiterate, and $21.3 \%$ were farmers (Table 1 ).

\section{TB patients}

Of the $844 \mathrm{~TB}$ patients interviewed, the mean (SD) age was 34 (13.8) years, and $29.7 \%$ were in the age range $18-30$ years. More than half (57.8\%) were males, $46.9 \%$ were heads of household, $51.4 \%$ were married, $24.1 \%$ were farmers, and $34.7 \%$ could not read and write (Table 1). The mean family size and number of people sleeping per room were 4.5 and 3.6, respectively. Among the TB patients, more than a third (37.4\%) had at least one child under the age of five.

\section{Attitudes about and stigma toward tuberculosis General population}

Almost two-thirds $(64.5 \%)$ of the study participants reported that they could cope with TB, but 31.9\% expressed fear. When asked who they would tell, $82.7 \%$ of participants reported that they would inform a doctor, while $21.5 \%$ would tell a spouse, $16.5 \%$ close friends, and $25.7 \%$ family members. The majority (95.8\%) of the participants reported that they would go to public facilities, 
Table 1 Sociodemographic characteristics of the study population in Ethiopia

\begin{tabular}{|c|c|c|c|c|c|c|c|}
\hline \multirow{2}{*}{ Variables } & \multirow[b]{2}{*}{ Categories } & \multicolumn{2}{|c|}{ General population } & \multicolumn{2}{|c|}{ Families of TB patients } & \multicolumn{2}{|c|}{ TB patients } \\
\hline & & Number & $\%$ & Number & $\%$ & Number & $\%$ \\
\hline \multirow[t]{2}{*}{ Gender } & Male & 835 & 46.8 & 407 & 48.7 & 488 & 57.8 \\
\hline & Female & 948 & 53.2 & 429 & 51.3 & 356 & 42.2 \\
\hline \multirow[t]{3}{*}{ Age in years } & $18-30$ & 872 & 48.9 & 405 & 48.4 & 251 & 29.7 \\
\hline & $31-60$ & 828 & 46.4 & 414 & 49.5 & 246 & 29.1 \\
\hline & $>60$ & 83 & 4.7 & 17 & 2.0 & 164 & 19.4 \\
\hline \multirow[t]{5}{*}{ Relationship } & Head & 869 & 48.7 & 329 & 39.4 & 93 & 11.0 \\
\hline & Spouse & 597 & 33.5 & 248 & 29.7 & 52 & 6.2 \\
\hline & Son/Daughter & 266 & 14.9 & 160 & 19.1 & 38 & 4.5 \\
\hline & Other relative & 44 & 2.5 & 88 & 10.5 & 396 & 46.9 \\
\hline & Non-relative & 7 & 0.4 & 11 & 1.3 & 189 & 22.4 \\
\hline \multirow[t]{5}{*}{ Marital Status } & Married & 1176 & 66 & 543 & 65.0 & 186 & 22.0 \\
\hline & Never married & 343 & 19.2 & 203 & 24.3 & 7 & 0.8 \\
\hline & Divorced & 143 & 8 & 46 & 5.5 & 4 & 0.5 \\
\hline & Widowed & 107 & 6 & 38 & 4.5 & 434 & 51.4 \\
\hline & Living together & 14 & 0.8 & 6 & 0.7 & 283 & 33.5 \\
\hline \multirow[t]{5}{*}{ Educational Status } & Illiterate & 537 & 30.1 & 283 & 33.9 & 66 & 7.8 \\
\hline & Read and write only & 128 & 7.2 & 51 & 6.1 & 57 & 6.8 \\
\hline & Primary & 517 & 29 & 227 & 27.2 & 4 & 0.5 \\
\hline & Secondary & 398 & 22.3 & 173 & 20.7 & 292 & 34.7 \\
\hline & Above secondary & 203 & 11.4 & 102 & 12.2 & 40 & 4.7 \\
\hline \multirow[t]{9}{*}{ Occupation } & Employed & 210 & 11.8 & 126 & 15.1 & 263 & 31.2 \\
\hline & House wife & 393 & 22 & 178 & 21.3 & 163 & 19.3 \\
\hline & Farmer & 322 & 18.1 & 178 & 21.3 & 85 & 10.1 \\
\hline & Daily laborer & 179 & 10 & 80 & 9.6 & 102 & 12.1 \\
\hline & Trader & 381 & 21.4 & 121 & 14.5 & 114 & 13.5 \\
\hline & Student & 136 & 7.6 & 84 & 10.0 & 203 & 24.1 \\
\hline & No job/dependent & 114 & 6.4 & 47 & 5.6 & 103 & 12.2 \\
\hline & House maid & 38 & 2.1 & 19 & 2.3 & 85 & 10.1 \\
\hline & Other & 10 & 0.6 & 3 & 0.4 & 109 & 12.9 \\
\hline \multirow[t]{5}{*}{ Wealth Quintile } & Lowest & 355 & 19.9 & 166 & 19.9 & 102 & 12.1 \\
\hline & Second & 350 & 19.6 & 169 & 20.2 & 18 & 2.1 \\
\hline & Third & 365 & 20.5 & 162 & 19.4 & 8 & 0.9 \\
\hline & Fourth & 352 & 19.7 & 173 & 20.7 & 168 & 19.9 \\
\hline & Highest & 361 & 20.2 & 166 & 19.9 & 169 & 20.0 \\
\hline
\end{tabular}

while $14 \%$ reported that they would go to private facilities. More than two-thirds (68.5\%) of the community felt compassion for TB patients, but $20.5 \%$ stated that TB patients are rejected by the community (Table 2).

Some participants (11.9\%) would keep TB disease secret, but $84.5 \%$ would disclose their status, and if they did so, $84.6 \%$ would tell family members. Of the participants, $18.1 \%$ reported that the community would think less of them, $24.2 \%$ said the community would avoid them, $15.1 \%$ said they would be asked to stay away, and $14.9 \%$ would be ashamed. Of the general population, $9.8 \%$ responded that they would not disclose TB disease to a confidant; $16.4 \%$ would think less of themselves, and $6.5 \%$ expected that family would think less of them (Table 3).

\section{Families of TB patients}

Among family members of TB patients, 514 (63.1\%) reported that they could get TB, and $558(68.5 \%)$ responded that they would cope with it if they did. Of the respondents, 
Table 2 Attitude and stigma towards tuberculosis among the general population

\begin{tabular}{|c|c|c|c|}
\hline Variables & & \# & $\%$ \\
\hline Do you think you can get TB $(n=1668)$ & & 756 & 45.3 \\
\hline Reaction if you were found out that you & Cope with it & 1076 & 64.5 \\
\hline & Fear & 532 & 31.9 \\
\hline & Surprise & 80 & 4.8 \\
\hline & Shame & 55 & 3.3 \\
\hline & Embarrassment & 33 & 2 \\
\hline & Sadness or hopelessness & 78 & 4.7 \\
\hline & Other & 9 & 0.5 \\
\hline Who would you talk to about your illness & Doctor/other medical worker & 1380 & 82.7 \\
\hline & Spouse & 358 & 21.5 \\
\hline & Parent & 450 & 27 \\
\hline & Children & 169 & 10.1 \\
\hline & Other family member & 428 & 25.7 \\
\hline & Close friend & 276 & 16.5 \\
\hline & No one & 18 & 1.1 \\
\hline & Others & 5 & 0.03 \\
\hline What would you do if you thought you had & Go to public health facility & 1598 & 95.8 \\
\hline & Go to private health facility & 233 & 14 \\
\hline & Go to pharmacy & 46 & 2.8 \\
\hline & Go to spiritual/traditional healer & 25 & 1.5 \\
\hline & Pursue other self-treatment options & 4 & 0.2 \\
\hline & Others & 2 & 0.1 \\
\hline & Don't know & 11 & 0.7 \\
\hline If you would not go to health facility, what is & Not sure where to go & 7 & 29.2 \\
\hline the reason? ( $N$ & Cost & 11 & 45.8 \\
\hline & Transportation related & 2 & 8.3 \\
\hline & Don't trust health workers & 4 & 16.7 \\
\hline & Would be cured by religion & 1 & 0.1 \\
\hline If you had symptoms of TB, at what point would & Immediately & 1080 & 64.7 \\
\hline you go to the health facility & In few days & 305 & 18.3 \\
\hline & One to 2 weeks & 172 & 10.3 \\
\hline & After 2 weeks & 93 & 5.6 \\
\hline & I will not go to health facility & 14 & 0.8 \\
\hline & Other & 4 & 0.2 \\
\hline How expensive do you think TB diagnosis and & It is free of charge & 782 & 46.9 \\
\hline & It is reasonably priced & 187 & 11.2 \\
\hline & It is moderately expensive & 139 & 8.3 \\
\hline & It is very expensive & 142 & 8.5 \\
\hline & Don't know & 418 & 25.1 \\
\hline Know people who have/had TB & & 815 & 48.9 \\
\hline Statement closest to your feeling about people & I feel compassion and desire to help & 1142 & 68.5 \\
\hline & $\begin{array}{l}\text { I feel compassion but tend to stay away } \\
\text { from these people }\end{array}$ & 208 & 12.5 \\
\hline & It is their problem and I don't want to get & 74 & 4.4 \\
\hline
\end{tabular}


Table 2 Attitude and stigma towards tuberculosis among the general population (Continued)

\begin{tabular}{|c|c|c|c|}
\hline Variables & & $\#$ & $\%$ \\
\hline \multirow{8}{*}{$\begin{array}{l}\text { How TB patient usually regarded/treated In your } \\
\text { community? }\end{array}$} & I fear them because they may infect me & 98 & 5.9 \\
\hline & I have no particular feeling & 145 & 8.7 \\
\hline & Other & 1 & 0.1 \\
\hline & Most people reject him/her & 342 & 20.5 \\
\hline & $\begin{array}{l}\text { Most people are friendly, but they generally } \\
\text { try to avoid }\end{array}$ & 295 & 17.7 \\
\hline & $\begin{array}{l}\text { The community mostly supports and helps } \\
\mathrm{him} / \mathrm{her}\end{array}$ & 683 & 40.9 \\
\hline & I don't have the experience & 345 & 20.7 \\
\hline & Others & 3 & 0.2 \\
\hline
\end{tabular}

$685(84.0 \%)$ reported that they would like to talk to medical personnel if they had TB. Some family members $(8.9 \%$, or 73) reported that they would not disclose their status even to a confidant (Additional file 1: Table S2).

Among family members, 637 (78.2\%) mentioned that they knew people who had TB, and 637 (78.2\%) reported that they would feel compassion and want to help them. Slightly more than half (432, or $53 \%$ ) of the respondents mentioned that the community supported and helped TB patients. Some of the respondents - 205 (25.2\%) and $176(21.6 \%)$-indicated that the community avoided and rejected them, respectively (Additional file 1: Table S1). One hundred and fifty-two (18.6\%) and 134 (16\%) respondents reported that others would avoid them and think less of them if they had TB, respectively.

\section{TB patients}

Most TB patients, $82.5 \%$ (679) reported that they would not disclose having TB to a confidant, while 107 (13\%) would not disclose. Two hundred and forty-seven (30\%) and 234 (28.5\%) reported that they would not find a job or would lose their job, respectively (Additional file 1: Table S3). Of 380 who had no partner, $15.8 \%$ reported that they would have a problem in finding a spouse even after their cure. Of 443 who had a partner, $46.5 \%$ reported that their partner would refuse to have sex with them. Of 361 participants who had children, $80.1 \%$ of them reported that being a TB patient is a problem for their children (Additional file 1: Table S3).

\section{Stigma score and factors associated with stigma General population}

The mean stigma score was 18.6 (range: 9-45). Of the respondents, 645 (38.7\%) had high stigma scores. A high stigma score was inversely correlated with educational status, region, and a high knowledge score. Addis Ababa had the lowest stigma score. Oromia had 10 times higher stigma compared to Addis Ababa (AOR: 0.1 [95\% CI: 0.06-0.17]). Compared to those who could not read and write, those who were educated above secondary school had a $42 \%$ lower mean stigma score (AOR: 0.58 [95\%CI: 0.39-0.87]). Respondents who had high knowledge scores had a

Table 3 Response of the general population to TB stigma related questions

\begin{tabular}{|c|c|c|c|c|c|c|}
\hline \multirow[t]{2}{*}{ Stigma related questions $(N=1668)$} & \multicolumn{2}{|c|}{ Agree } & \multicolumn{2}{|c|}{ Indifferent } & \multicolumn{2}{|c|}{ Disagree } \\
\hline & \# & $\%$ & \# & $\%$ & \# & $\%$ \\
\hline If yourself got TB, you would want it to remain secret. & 198 & 11.9 & 61 & 3.7 & 1409 & 84.5 \\
\hline $\begin{array}{l}\text { If a member of your family got TB, you would want it } \\
\text { to remain secret. }\end{array}$ & 194 & 11.6 & 63 & 3.8 & 1411 & 84.6 \\
\hline If you had TB, others would think less of you. & 302 & 18.1 & 164 & 9.8 & 1202 & 72.1 \\
\hline If you had TB, you would be ashamed or embarrassed. & 250 & 14.9 & 79 & 4.7 & 1339 & 80.3 \\
\hline If you had TB, others would avoid you. & 403 & 24.2 & 205 & 12.3 & 1060 & 63.6 \\
\hline $\begin{array}{l}\text { If you had TB, you would be asked to stay away from a } \\
\text { social group. }\end{array}$ & 251 & 15.1 & 191 & 11.5 & 1226 & 73.5 \\
\hline $\begin{array}{l}\text { If you had TB, you would not disclose even to a } \\
\text { confidant }\end{array}$ & 164 & 9.8 & 91 & 5.5 & 1413 & 84.7 \\
\hline If you had TB, you would think less of yourself. & 273 & 16.4 & 108 & 6.5 & 1287 & 77.2 \\
\hline If you had TB, others would think less of your family. & 109 & 6.5 & 43 & 2.6 & 1516 & 90.9 \\
\hline
\end{tabular}

A total of nine items were used to assess stigma and they had high internal consistency (Cronbach's alpha $=0.98$ ) 
lower $38 \%$ odds of having a high stigma score (AOR: 0.62 [95\% CI: 0.49-0.78]) (Table 4).

\section{Families of TB patients}

The mean stigma score was 20.46 (range: 10-46). Of the family members, $310(38.0 \%)$ had high stigma scores. A high stigma score was associated with educational status and region. Respondents who had completed primary school (AOR: 0.6: 95\% CI: 0.39-0.93), secondary school (AOR: 0.52; 95\% CI: 0.32-0.84), and above secondary school education (AOR: 0.37: 95\% CI: 0.23-0.61) were less likely to have high stigma scores compared to those who could not read and write. High stigma scores were observed in Oromia Region compared to other regions of Ethiopia (Additional file 1: Table S4).

\section{TB patients}

The mean stigma score was 21.31 (range: 9-45). Of the 844 TB patients, 356 (43.3\%) had high stigma scores. A high stigma score was associated with educational status, wealth status, and region. Oromia Region had the highest and Addis Ababa had the least mean stigma scores. Compared to those who could not read and write, those with secondary school education had a 39\% lower odds of having high stigma scores. TB patients in the first (AOR: 1.93: 95\%CI 1.05-3.57) and third quintiles (AOR: 1.81: 95\%CI: 1.08-3.05) had stigma scores twice as high as those in the highest wealth quintile (Additional file 1: Table S5).

Of the TB patients, $75.5 \%$ felt that family members were supportive. Most of the patients (75.3\%) perceived that their utensils were separated. Close to half of TB patients $(45.9 \%)$ feared reduced family income due to their condition, while $37 \%$ felt increased sadness, $32.5 \%$ felt the threat of losing their jobs, $25.4 \%$ mentioned that people behaved differently toward them, and $15.3 \%$ felt isolated within the family. Some $(9.3 \%)$ felt avoided by family members (Table 5). Three-quarters $(75.7 \%)$ of $\mathrm{TB}$ patients reported that they felt compassion for and a desire to help other TB patients, $7 \%$ reported no particular feeling, and

Table 4 Factors associated with stigma towards tuberculosis in the general population

\begin{tabular}{|c|c|c|c|c|c|}
\hline \multirow[t]{2}{*}{ Variables } & & \multirow{2}{*}{$\begin{array}{l}\text { Stigma High } \\
\text { \# (\%) }\end{array}$} & \multirow{2}{*}{$\begin{array}{l}\text { Stigma Low } \\
\#(\%)\end{array}$} & \multirow[t]{2}{*}{ COR $(95 \% \mathrm{Cl})$} & \multirow[t]{2}{*}{ AOR $(95 \% \mathrm{Cl})$} \\
\hline & & & & & \\
\hline \multirow[t]{2}{*}{ Gender } & Male & $293(37.4)$ & $490(62.6)$ & $0.91(0.74-1.1)$ & NA \\
\hline & Female & $352(39.8)$ & $533(60.2)$ & 1 & \\
\hline \multirow[t]{5}{*}{ Education } & Not able to read and write & $220(46.5)$ & $253(53.5)$ & 1 & 1 \\
\hline & Read and write only & $48(40.7)$ & 70 (59.3) & $0.79(0.52-1.19)$ & $0.9(.57-1.38)$ \\
\hline & Primary & $180(37.0)$ & $306(63.0)$ & $0.68(0.52-0.88)$ & $0.84(.63-1.11)$ \\
\hline & Secondary & $143(36.8)$ & $246(63.2)$ & $0.67(0.51-0.88)$ & $0.92(0.68-1.25)$ \\
\hline & Above secondary & $54(26.7)$ & $148(73.3)$ & $0.42(0.29-0.6)$ & $0.58(0.39-0.87)^{\mathrm{a}}$ \\
\hline \multirow[t]{5}{*}{ Wealth } & Lowest & $122(39.9)$ & $184(60.1)$ & $1.53(1.11-2.11)$ & $0.83(0.55-1.25)$ \\
\hline & Second & $146(45.3)$ & $176(54.7)$ & $1.91(1.4-2.62)$ & $0.97(0.65-1.43)$ \\
\hline & Third & $137(40.7)$ & $200(59.3)$ & $1.58(1.15-2.16)$ & $0.88(0.61-1.28)$ \\
\hline & Fourth & $132(38.2)$ & $214(61.8)$ & $1.42(1.04-1.95)$ & $0.85(0.6-1.2)$ \\
\hline & Highest & $108(30.3)$ & $249(69.7)$ & 1 & 1 \\
\hline \multirow[t]{2}{*}{ Setting } & Rural & $314(42.5)$ & $425(57.5)$ & $1.33(1.1-1.63)$ & $0.95(0.75-1.21)$ \\
\hline & Urban & $331(35.6)$ & $598(64.4)$ & 1 & 1 \\
\hline \multirow[t]{2}{*}{ Knowledge score } & High & $280(33.5)$ & $555(66.5)$ & $0.65(0.53-0.79)$ & $0.62(0.49-0.78)^{a}$ \\
\hline & Low & $365(43.8)$ & $468(56.2)$ & 1 & 1 \\
\hline \multirow[t]{9}{*}{ Region } & Oromia & $192(58.4)$ & $137(41.6)$ & 1 & 1 \\
\hline & Amhara & $121(36.1)$ & $214(63.9)$ & $0.4(0.3-0.55)$ & $0.35(0.25-0.49)^{\mathrm{a}}$ \\
\hline & SNNP & $81(25.5)$ & $237(74.5)$ & $0.24(0.18-0.34)$ & $0.23(0.16-0.32)^{\mathrm{a}}$ \\
\hline & Tigray & $95(53.7)$ & $82(46.3)$ & $0.83(0.57-1.19)$ & $0.8(0.55-1.17)$ \\
\hline & Benshangul Gumuz & $43(48.3)$ & $46(51.7)$ & $0.67(0.42-1.07)$ & $0.61(0.37-0.98)^{a}$ \\
\hline & Gambella & $19(23.2)$ & $63(76.8)$ & $0.22(0.12-0.38)$ & $0.22(0.12-0.38)^{a}$ \\
\hline & Addis Ababa & $22(12.7)$ & $151(87.3)$ & $0.1(0.06-0.17)$ & $0.1(0.06-0.17)^{a}$ \\
\hline & Dire Dawa & $35(43.2)$ & $46(56.8)$ & $0.54(0.33-0.89)$ & $0.54(0.33-0.91)^{\mathrm{a}}$ \\
\hline & Harari & $37(44.0)$ & $47(56.0)$ & $0.56(0.35-0.91)$ & $0.54(0.32-0.88)^{a}$ \\
\hline
\end{tabular}

${ }^{a}$ Statistically significant. The study participants were grouped as having high and low stigma score using the mean stigma score as a cut-off point 
Table 5 Perception of TB patients regarding their relationships and livelihood

\begin{tabular}{|c|c|c|c|c|c|c|}
\hline \multirow{2}{*}{$\begin{array}{l}\text { Variables } \\
N=823\end{array}$} & \multicolumn{2}{|c|}{ Agree } & \multicolumn{2}{|c|}{ Indifferent } & \multicolumn{2}{|c|}{ Disagree } \\
\hline & $\#$ & $\%$ & $\#$ & $\%$ & $\#$ & $\%$ \\
\hline Family members are cooperative towards me & 621 & 75.5 & 33 & 4.0 & 169 & 20.6 \\
\hline Utensils are separated for me & 620 & 75.3 & 27 & 3.3 & 176 & 21.4 \\
\hline I have fear of reduction of family income & 378 & 45.9 & 75 & 9.1 & 370 & 44.9 \\
\hline Threat of loss of job/wages & 267 & 32.5 & 84 & 10.2 & 472 & 57.4 \\
\hline Most people behave differently & 209 & 25.4 & 67 & 8.1 & 547 & 66.5 \\
\hline Feel isolated within the family & 126 & 15.3 & 49 & 6.0 & 648 & 78.8 \\
\hline Family members avoid me & 76 & 9.3 & 36 & 4.4 & 711 & 86.4 \\
\hline I have increased sadness & 305 & 37.1 & 79 & 9.6 & 439 & 53.4 \\
\hline
\end{tabular}

$17.2 \%$ reported that they would stay away because of fear of re-infection (Additional file 1: Table S3).

\section{Socioeconomic consequences of TB on the patients}

Of the $844 \mathrm{~TB}$ patients, $64.9 \%$ reported that nothing had happened after they developed TB. However, 8.9\% TB patients lost their jobs, $21 \%$ encountered a reduction in income, $1.5 \%$ divorced, and 3.4\% interrupted school.

\section{Qualitative findings}

The community felt that $\mathrm{TB}$ is a serious disease and treatment takes a long time, and they feared acquiring TB. People were afraid to share utensils with TB patients and sit near a TB patient who has a cough. Participants mentioned that TB patients are isolated or discriminated as against because TB is infectious and a communicable disease.

“...TB patients have difficulty of getting houses to rent because of the fear of transmission of TB to people who live in the same compound..." (Addis Ababa, Female, FGD).

"My husband's family stigmatized me a lot. Since they knew that I am a TB patient, they didn't sleep in our house. They sleep outdoors. They are not also willing to eat with me. ...Before I was infected with TB, our social life with other people was great. The social life of DD community is well known. But after they knew that I am a TB patient, only one of my neighbors sometimes comes to visit me. In order not to come to my house frequently, she used to say I am tired and I have a lot of work to do at home" (Dire Dawa, Female TB patient).

"...acquiring TB may be considered as a curse..." (Addis Ababa, Female, FGD).

Some participants reported that the extent of stigmatization and isolation of TB patients has significantly decreased these days because people know that it is curable. TB patients are not prohibited from obtaining services in the community due to their illness.

"We should not discriminate [against] TB patients, rather we should help them with diets, proper care and anything else they require..." (Southern Nations, Nationalities, and Peoples' Region, Male, FGD).

Family members reported that they supported TB patients by providing nutritious food, arranging a separate bedroom, accompanying them when they go to collect drugs from the health centers/health posts, and allowing them to have adequate rest.

\section{Discussion}

We report high fear of $\mathrm{TB}$ and stigma in the general population of Ethiopia, which are reflected by the community's perception of TB patients and selfstigmatization by patients. Stigma is associated with educational status, level of awareness about TB, and wealth status, and its levels varied across regions.

Stigma related to TB is a perceived and/or internalized attitude of a community or families toward TB patients due to social norms. The poor, women, ethnic minorities, migrants, and refugees were reported to be highly affected by TB-related stigma and its consequences, including isolation, lack of support, and loss of employment, depending on the cultural context and level of awareness in the community $[18,19,25,26]$.

Community perceptions about TB can positively or negatively affect the capacity of the community to offer support to TB patients and the effectiveness of TB programs [18]. In settings where understanding and caring exist, the capacity of TB patients to seek care, adhere to treatment, and receive support [27]. Perceptions are shaped by knowledge about the disease, capacity to seek care, and factors affecting this capacity. Unfortunately, despite the existence of free and decentralized TB services, the attitudes, perceptions, and reactions of the 
community toward TB patients have affected service delivery and could result in delayed care seeking and affect treatment outcomes $[5,28]$. TB remains a highly stigmatized disease, mainly because of its association with HIV and misconceptions about its transmission. This is confirmed by qualitative findings that TB patients were denied housing and sometimes the disease was considered a curse. In such communities, the capacity to access care is compromised and patients tend to remain at home rather than seek care when they develop symptoms.

As in our study, high self-disclosure to family members was reported from Nigeria. However, they believed that TB is an embarrassment to the family and did not share utensils or beds [29]. This could be due to TBassociated stigma within the community and associated consequences.

Perceptions about the disease also affect patients' capacity to cope with it. In our study, $60 \%$ reported that they could cope with TB. The patients think less of themselves, however, and experience problems related to social engagement, employment, marriage, feelings of sadness, depression. and self-stigmatization [19, 30]. A study from Zambia found that stigma results in low self-esteem, affects disclosure capacity, and has social consequences for patients and their children, [15] findings that merit implementation of stigma reduction interventions.

Urban areas have higher knowledge about $\mathrm{TB}$, which is reflected by lower stigma. However, in areas with high HIV prevalence, the opposite scenario existed, due to HIV-related stigma [8]. In other contexts, high knowledge scores were not paralleled by low stigma, which requires further study.

Stigma shapes the disclosure of TB status within a community. From the qualitative part of the study, we learned TB is sometimes considered a curse, which makes it more difficult for patients and households to disclose it to the community. Therefore, TB patients mainly disclosed their TB status to family members [31]. However, disclosure was affected by patients' perception that they would not be stigmatized. Patients' trust in the family and the community played a crucial role in supporting disclosure. In our study, the majority of study participants reported that they would seek public health facilities and disclose their symptoms to doctors. This could be due to low HIV-associated TB in rural communities, where patients dare to seek care and share information with health workers.

Patients affected by TB expressed stigma within the household, as reported from the FGDs in the qualitative part of the study. They indicated that the family members were not willing to share utensils or eat with them. More than the stigma from the community and families, internalized stigma by TB patients (self-stigmatization) plays an important role in care seeking and social engagement [10]. The fact that TB patients expect rejection by the community if they are known to have TB requires intervention to ensure that patients are accepted and supported when seeking care. This could be done through the decentralization of services, better health education about TB, and community support to patients. Engaging community HEWs and Ethiopia's Health Development Army that reaches households is crucial to enhance the level of community support for patients. This is reflected in the qualitative part of the study, which underscores the importance of supporting TB patients in the community.

Ethiopia's high TB burden may be due in part to TBrelated stigma and perceptions about TB and sociocultural factors, as another study from Ethiopia has found [18]. The NTP needs to develop a stigma reduction strategy to reduce this barrier to seeking care. Stigma is associated with wealth, educational status, setting (rural/ urban), and knowledge that TB is a preventable and curable disease, so tailored interventions are needed to the reach cases in the community missed as a result of stigma [19].

\section{Limitations of the study}

This is the first national study about TB-related stigma in Ethiopia. However, cultural and socioeconomic conditions might have affected the understanding and expression of stigma in the communities. The interviewers speak the local language, created conducive environment and encouraged better communication by giving opportunities to compensate for this.

\section{Conclusions}

TB-related stigma remains a challenge to TB prevention and control in Ethiopia. Therefore, tailored stigma reduction interventions are needed to increase community awareness about TB, improve health-seeking behavior, and promote support for TB patients in their households and the community.

\section{Supplementary information}

Supplementary information accompanies this paper at https://doi.org/10. 1186/s12889-019-7915-6.

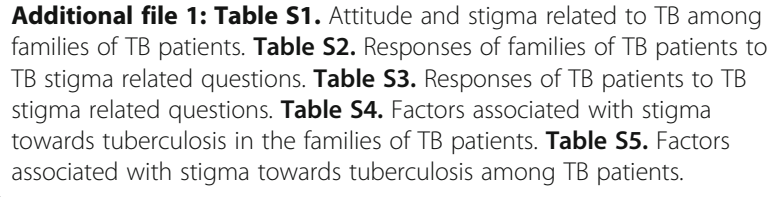

Additional file 1: Table S1. Attitude and stigma related to TB among families of TB patients. Table S2. Responses of families of TB patients to TB stigma related questions. Table S3. Responses of TB patients to TB stigma related questions. Table S4. Factors associated with stigma towards tuberculosis in the families of TB patients. Table S5. Factors associated with stigma towards tuberculosis among TB patients.

\section{Abbreviations}

DOTS: Directly observed treatment, short course; FGD: Focus group discussion; HEW: Health extension worker; HIV: Human immunodeficiency virus; IDI: In-depth interview; NTP: National Tuberculosis Programme; TB: Tuberculosis; WHO: World Health Organization 


\section{Acknowledgements}

We would like to thank ABH Services, which was commissioned by USAID/ Challenge TB to conduct this survey. We are grateful to the field supervisors and data collectors for their work and to the health workers and communities who participated in the study. We would like to thank Amha Hadgu for doing the statistical analysis and Nebiyu Hiruy for reviewing the data analysis. Barbara Timmons edited the paper.

\section{Authors' contributions}

DJ and PS designed the study. DGD supervised the data collection. DGD wrote the manuscript. All authors reviewed and approved the final version.

\section{Funding}

This research study was made possible by the generous support of the American people through the United States Agency for International Development, through the Challenge TB Project under agreement number AID-OAA-A-14-00029.

The funding body has no role in the design of the study, data collection, analysis, interpretation of the data and write up of the manuscript.

\section{Availability of data and materials}

The datasets used and/or analysed during the current study available from the corresponding author on reasonable request.

\section{Ethics approval and consent to participate}

This study was approved by the Ethiopian Science and Technology Commission, Ethics Review Board. We also obtained letters of support from the National TB Programme of the Federal Ministry of Health and Regional State Health Bureaus to conduct the study in the respective provinces, districts, health facilities, and communities. The study participants were recruited after obtaining informed consent, approved by review board.

\section{Consent for publication}

Not applicable.

\section{Competing interests}

The authors declare no conflict of interest.

\section{Author details}

'Challenge TB/Ethiopia and Management Sciences for Health/Ethiopia, P.O. Box 1157, Code 1250 Addis Ababa, Ethiopia. ${ }^{2}$ Management Sciences for Health, Senior Director Infectious Diseases Cluster, Arlington, USA.

Received: 19 June 2019 Accepted: 7 November 2019

Published online: 06 February 2020

\section{References}

1. Shivapujimath R, Rao AP, Nilima AR, Shilpa DM. A cross-sectional study to assess the stigma associated with tuberculosis among tuberculosis patients in Udupi district, Karnataka. Indian J Tuberc. 2017;64(4):323-6.

2. Abebe G, Deribew A, Apers L, Woldemichael K, Shiffa J, Tesfaye M, et al. Knowledge, health seeking behavior and perceived stigma towards tuberculosis among tuberculosis suspects in a rural community in Southwest Ethiopia. PLoS One. 2010;5(10):e13339.

3. Johansson E, Long NH, Diwan VK, Winkvist A. Gender and tuberculosis control: perspectives on health seeking behaviour among men and women in Vietnam. Health Policy. 2000;52(1):33-51.

4. Zhang T, Liu X, Bromley H, Tang S. Perceptions of tuberculosis and health seeking behaviour in rural Inner Mongolia, China. Health Policy. 2007:81(2):155-65.

5. Courtwright A, Turner AN. Tuberculosis and stigmatization: pathways and interventions. Public Health Rep. 2010;125(Suppl 4):34-42.

6. Heijnders $M$, Van Der Meij $\mathrm{S}$. The fight against stigma: an overview of stigma-reduction strategies and interventions. Psychol Health Med. 2006; 11(3):353-63.

7. Dako-Gyeke M. Courtesy stigma: a concealed consternation among caregivers of people affected by leprosy. Soc Sci Med. 2018;196:190-6.

8. Daftary A. HIV and tuberculosis: the construction and management of double stigma. Soc Sci Med. 2012;74(10):1512-9.

9. Godfrey-Faussett P, Ayles H. Can we control tuberculosis in high HIV prevalence settings? Tuberculosis (Edinburgh, Scotland). 2003;83(1-3):68-76.
10. Macq J, Solis A, Martinez G, Martiny P. Tackling tuberculosis patients' internalized social stigma through patient centred care: an intervention study in rural Nicaragua. BMC Public Health. 2008;8:154.

11. Macq J, Solis A, Martinez G, Martiny P, Dujardin B. An exploration of the social stigma of tuberculosis in five "municipios" of Nicaragua to reflect on local interventions. Health Policy. 2005;74(2):205-17.

12. Barnhoorn $F$, Adriaanse $H$. In search of factors responsible for noncompliance among tuberculosis patients in Wardha District, India. Soc Sci Med. 1992;34(3):291-306.

13. Edginton ME, Sekatane CS, Goldstein SJ. Patients' beliefs: do they affect tuberculosis control? A study in a rural district of South Africa. Int J Tuberc Lung Dis. 2002;6(12):1075-82.

14. Jaramillo E. Pulmonary tuberculosis and health-seeking behaviour: how to get a delayed diagnosis in Cali, Colombia. Tropical Med Int Health. 1998; 3(2):138-44.

15. Cremers AL, de Laat MM, Kapata N, Gerrets R, Klipstein-Grobusch K, Grobusch MP. Assessing the consequences of stigma for tuberculosis patients in urban Zambia. PLoS One. 2015;10(3):e0119861.

16. Liefooghe R, Michiels N, Habib S, Moran MB, De Muynck A. Perception and social consequences of tuberculosis: a focus group study of tuberculosis patients in Sialkot, Pakistan. Soc Sci Med. 1995;41(12):1685-92.

17. Baral SC, Karki DK, Newell JN. Causes of stigma and discrimination associated with tuberculosis in Nepal: a qualitative study. BMC Public Health. 2007;7:211.

18. Juniarti N, Evans D. A qualitative review: the stigma of tuberculosis. J Clin Nurs. 2011;20(13-14):1961-70.

19. Miller C, Huston J, Samu L, Mfinanga S, Hopewell P, Fair E. IIt makes the patient's spirit weaker': tuberculosis stigma and gender interaction in Dar Es Salaam, Tanzania. Int J Tuberc Lung Dis. 2017;21(11):42-8.

20. Godfrey-Faussett P, Ayles H. The impact of HIV on tuberculosis control-towards concerted action. Lepr Rev. 2002;73(4):376-85.

21. Hudelson P. Gender differentials in tuberculosis: the role of socio-economic and cultural factors. Tuber Lung Dis. 1996;77(5):391-400.

22. Rubel AJ, Garro LC. Social and cultural factors in the successful control of tuberculosis. Public Health Rep. (Washington, DC : 1974. 1992:107(6):626-36.

23. Yin $X$, Yan S, Tong $Y$, Peng $X$, Yang $T$, Lu Z, et al. Status of tuberculosis-related stigma and associated factors: a cross-sectional study in Central China. Tropical Med Int Health. 2018;23(2):199-205.

24. Agency CS. Ethiopia demographic and health survey 2011; 2011.

25. WHO/HTM/STB. Advocay, communication and social mobilization for TB control: a guide to developing knowledge, attitude and practice surveys Geneva, Switzerland. 2008.

26. Sengupta $S$, Pungrassami $P$, Balthip $Q$, Strauss $R$, Kasetjaroen $Y$, Chongsuvivatwong $\mathrm{V}$, et al. Social impact of tuberculosis in southern Thailand: views from patients, care providers and the community. Int J Tuberc Lung Dis. 2006;10(9):1008-12.

27. Van Brakel WH. Measuring health-related stigma--a literature review. Psychol Health Med. 2006;11(3):307-34.

28. Chowdhury MR, Rahman MS, Mondal MN, Sayem A, Billah B. Social impact of stigma regarding tuberculosis hindering adherence to treatment: a cross sectional study involving tuberculosis patients in Rajshahi City, Bangladesh. Jpn J Infect Dis. 2015;68(6):461-6.

29. Liefooghe R, Baliddawa JB, Kipruto EM, Vermeire C, De Munynck AO. From their own perspective. A Kenyan community's perception of tuberculosis. Tropical Med Int Health. 1997;2(8):809-21.

30. AOO KYA, Goodman OO, Odusanya OO. Knowledge of Tuberculosis and Self Disclosure amongst Patients Accessing Treatment in an Urban Local Government Area, Lagos, South West Nigeria. J Commun Med Prim Health Care. 2016;28(2):34-9.

31. Lee LY, Tung HH, Chen SC, Fu CH. Perceived stigma and depression in initially diagnosed pulmonary tuberculosis patients. J Clin Nurs. 2017;26(23-24):4813-21.

32. Zolowere D, Manda K, Panulo Jr B, Muula A. Experiences of self-disclosure among tuberculosis patients in rural Southern Malawi. Rural and Remote Health 2008;8:1037. Available: www.rrh.org.au/journal/article/1037.

\section{Publisher's Note}

Springer Nature remains neutral with regard to jurisdictional claims in published maps and institutional affiliations. 